\title{
Sexually dimorphic and radiation dose dependent effect of cranial irradiation on body mass index
}

\author{
F Craig, A D Leiper, R Stanhope, C Brain, S T Meller, S S Nussey
}

\begin{abstract}
Objectives-To investigate the relation between cranial irradiation received during treatment for childhood leukaemia and obesity at final height.

Design-Retrospective cross sectional study.

Setting-Paediatric oncology centres at Great Ormond Street Hospital for Children and the Royal Marsden Hospital.

Subjects-Survivors of childhood leukaemia who received cranial irradiation, were in continuous first remission, and had reached final height. An unirradiated group of patients from the United Kingdom acute lymphoblastic leukaemia XI trial was also included; these patients were in continuous first remission and had been followed for at least four years from diagnosis.

Main outcome measures-Body mass index standard deviation score (BMI $\mathrm{z}$ score) at final height for irradiated patients and at most recent follow up for unirradiated patients. Regression analysis was used to examine the effect on BMI $z$ score of sex, age at diagnosis, and the dose of radiation received.
\end{abstract}

Results-For cranially irradiated patients, an increase in the BMI $\mathrm{z}$ score at final height was associated with female sex and lower radiation dose, but not with age at diagnosis. Severe obesity, defined as a BMI $z$ score of $>3$ at final height, was only present in girls who received 18-20 Gy irradiation and had a prevalence of $8 \%$. Both male and female unirradiated patients had raised BMI $\mathrm{z}$ scores at latest follow up and there was no association with age at diagnosis.

Conclusions-These data are further evidence for a sexually dimorphic and dose dependent effect of radiation on the human brain.

(Arch Dis Child 1999;81:500-504)

Keywords: acute lymphoblastic leukaemia; cranial irradiation; body mass index; obesity; sexual dimorphism

Endocrinology, Great Ormond Street

Hospital for Children R Stanhope

Department of Paediatric Oncology, The Royal Marsden Hospital, Sutton SM2 5PT, UK

S T Meller

Correspondence to: Dr Craig.

Accepted 19 January 1999 steady increase in long term survival. However, intravenously and intrathecally administered methotrexate and cranial radia-
Acute lymphoblastic leukaemia (ALL) is the single most common childhood malignancy in the UK is affected each year. Central nervous system (CNS) treatment has been an essential component in preventing meningeal relapse and its introduction contributed to tion treatment can have serious sequelae, including growth and endocrine dysfunction, ${ }^{45}$ cerebral structural changes, ${ }^{67}$ and cognitive impairment. ${ }^{8}$ Several mechanisms of delayed radiation induced CNS damage have been demonstrated. ${ }^{9}{ }^{10}$ Direct damage to endothelial cells can lead to alterations of capillary wall structure and permeability, resulting in alterations in cerebral blood flow. ${ }^{11}$ There is also evidence for primary damage to glial cells ${ }^{12}$ and of an autoimmune reaction to antigens released from damaged cells. ${ }^{13}$ Alterations in CNS neurotransmitter ${ }^{14}$ and biochemical function ${ }^{15}$ have also been reported.

There is increasing evidence that the deleterious effects of CNS directed treatment depend on the dose of radiation administered and the age of the patient. ${ }^{16-18}$ In addition, there is evidence that girls are affected more than boys. Girls perform less well than boys in tests of cognitive function ${ }^{19}{ }^{20}$ and have a higher incidence of premature and precocious puberty, ${ }^{21}$ both of which are more common in children treated at a young age.

Because there have been reports of obesity in long term survivors of leukaemia treatment, ${ }^{22-24}$ we examined whether weight gain and obesity are also age, radiation dose, and sex dependent.

\section{Patients and methods}

PATIENTS

Patients were treated for ALL at Great Ormond Street Hospital for Children between 1971 and 1994, or The Royal Marsden Hospital between 1974 and 1994. Patients were eligible for the study only if they had completed treatment and were in continuous first remission. Cranially irradiated patients were only included if they had reached final height and unirradiated patients were only included if they had been followed up for at least four years from the time of diagnosis. Hospital computerised records identified 370 cranially irradiated patients who were at least 13 years of age and therefore likely to be at final height. One hundred and fifty seven of these patients were excluded from the study because height and weight data were incomplete, patients had not been followed up to final height, or they had relapsed. One hundred and six unirradiated patients were identified, 21 of whom were subsequently excluded either because they were no longer in continuous first remission or because height and weight records were incomplete. Two hundred and thirteen ( 86 boys, 127 girls) irradiated patients and 85 (37 boys, 48 girls) unirradiated patients were enrolled in the study. Height and weight data were recorded at diagnosis and at the end of treatment in both 
Table 1 Mean age at the start of treatment, duration of treatment, and length of follow up of leukaemia survivors

\begin{tabular}{|c|c|c|c|c|c|c|c|c|}
\hline \multirow[b]{2}{*}{ Irradiation dose } & \multicolumn{2}{|c|}{$\begin{array}{l}\text { Number of } \\
\text { patients }\end{array}$} & \multicolumn{2}{|c|}{$\begin{array}{l}\text { Age at start of treatment } \\
\text { (range) }\end{array}$} & \multicolumn{2}{|c|}{$\begin{array}{l}\text { Duration of treatment } \\
\text { (range) }\end{array}$} & \multicolumn{2}{|c|}{$\begin{array}{l}\text { Length of follow up from star } \\
\text { of treatment (range) }\end{array}$} \\
\hline & Boys & Girls & Boys & Girls & Boys & Girls & Boys & Girls \\
\hline $18-20 \mathrm{~Gy}$ & 45 & 73 & $\begin{array}{l}6.0 \\
(1.7-15.3)\end{array}$ & $\begin{array}{l}5.2 \\
(0.5-12.5)\end{array}$ & $\begin{array}{l}2.2 \\
(1.8-3.2)\end{array}$ & $\begin{array}{l}2.2 \\
(1.7-4.0)\end{array}$ & $\begin{array}{l}12.3 \\
(3.9-19.2)\end{array}$ & $\begin{array}{l}10.7 \\
(4.9-16.1)\end{array}$ \\
\hline $22-24$ Gy & 41 & 54 & $\begin{array}{l}4.9 \\
(1.3-12.2)\end{array}$ & $\begin{array}{l}5.9 \\
(1.8-15.5)\end{array}$ & $\begin{array}{l}2.4 \\
(1.8-4.2)\end{array}$ & $\begin{array}{l}2.3 \\
(1.6-3.1)\end{array}$ & $\begin{array}{l}13.4 \\
(5.8-18.8)\end{array}$ & $\begin{array}{l}10.5 \\
(3.4-15.8)\end{array}$ \\
\hline No irradiation & 37 & 48 & $\begin{array}{l}4.1 \\
(0.2-10.3)\end{array}$ & $\begin{array}{l}4.5 \\
(0.6-13)\end{array}$ & $\begin{array}{l}1.9 \\
(1.6-2.2)\end{array}$ & $\begin{array}{l}2.0 \\
(1.5-2.3)\end{array}$ & $\begin{array}{l}4.9 \\
(4.0-7.1)\end{array}$ & $\begin{array}{l}4.7 \\
(4.0-7.9)\end{array}$ \\
\hline
\end{tabular}

Ages are in years.

patient groups, at final height in irradiated subjects, and at most recent follow up in unirradiated subjects. Table 1 summarises patient details.

Children receiving 18-20 Gy cranial irradiation were treated with chemotherapy regimens that included a variety of Great Ormond Street Hospital devised and Medical Research Council (MRC) protocols, UKALL III-VI, and UKALL VIII-X. Children receiving 22-24 Gy cranial irradiation were treated with similar Great Ormond Street devised and MRC protocols, UKALL I-VI, and UKALL VIII-X. Unirradiated children were treated on the MRC protocol UKALL XI, with the exception of two boys who were treated on an infant ALL protocol. Unirradiated patients all received intrathecal methotrexate either alone or combined with high dose intravenous methotrexate.

Chemotherapy regimens consisted of induction of remission and continuation treatment. Most patients also had one or two chemotherapy intensification blocks and some of the unirradiated patients also received a third intensification block. Induction chemotherapy included vincristine, asparaginase, and prednisolone and, in some patients, additional daunorubicin or cytosine arabinoside. All patients received intrathecal methotrexate. Continuation treatment usually consisted of daily mercaptopurine and weekly methotrexate, with monthly pulses of vincristine and prednisolone.

Body mass index (BMI), defined as weight in $\mathrm{kg}$ divided by height in $\mathrm{m}^{2}$, was calculated for each patient at the start of treatment, at the end of treatment, and at final height (irradiated patients), or at the most recent follow up (unirradiated patients). Final height was defined as the standing height achieved when the linear growth velocity during the preceding year was $<1 \mathrm{~cm} /$ year. A BMI standard deviation score (BMI z score) was calculated for each value using age and sex matched population standards ${ }^{25}$ and the formula devised by Cole and Green, ${ }^{26}$ which takes into account changes in the skewness of the distribution of BMI data in relation to age. Obesity was defined as being present when the BMI $\mathrm{z}$ score was $>2$ and severe obesity as a BMI z score of $>3$.

STATISTICAL ANALYSIS

Unirradiated patients had not been followed up to final height and were therefore assessed separately. For irradiated patients, regression analysis was used to determine the effects on BMI z score at final height of sex, age at diagnosis, and the dose of radiation received. For unirradiated patients, regression analysis was used to determine the effects of sex and age at diagnosis on BMI z score at last follow up. Single sample $t$ tests were used to determine whether BMI z scores were raised at the start of treatment, end of treatment, and at final height, or last follow up. Paired $t$ tests were used to determine whether changes in BMI $\mathrm{z}$ score occurred during treatment and/or between the end of treatment and final height or last follow up.

\section{Results}

CRANIALLY IRRADIATED PATIENTS

Regression analysis was used to determine the effect on BMI z score at final height of age at diagnosis, sex, and the dose of radiation received, taking into account BMI $\mathrm{z}$ score at the start of treatment. Sex and radiation dose, but not age at diagnosis, were significant factors. BMI $\mathrm{z}$ scores at final height were significantly higher in girls than boys $(p=0.01)$ and in patients who received a lower radiation dose $(p=0.01)$. Therefore, for further analysis, patients were stratified according to sex and radiation dose received, 18-20 Gy and 22-24 Gy (table 2). Girls who received 22-24 Gy cranial irradiation and boys who received $18-20$ Gy radiation had significantly

Table 2 Mean body mass index standard deviation (BMI z) score of cranially irradiated patients

\begin{tabular}{|c|c|c|c|c|c|}
\hline \multirow[b]{2}{*}{ Irradiation dose and sex } & \multicolumn{3}{|c|}{$\begin{array}{l}\text { Mean (SE) patient BMI } z \text { score [p value for difference } \\
\text { from population standards] }\end{array}$} & \multicolumn{2}{|c|}{$\begin{array}{l}p \text { Value for change in BMI } z \text { score during treatment } \\
\text { and between end of treatment and final height }\end{array}$} \\
\hline & Diagnosis & End of treatment & Final height & $\begin{array}{l}\text { Diagnosis to end of } \\
\text { treatment }\end{array}$ & $\begin{array}{l}\text { End of treatment to final } \\
\text { height }\end{array}$ \\
\hline Girls 18-20 Gy & $\begin{array}{l}-0.24(0.15) \\
{[0.1]}\end{array}$ & $\begin{array}{l}0.46(0.11) \\
{[<0.0001]}\end{array}$ & $\begin{array}{l}0.90(0.14) \\
{[<0.0001]}\end{array}$ & $<0.0001$ & $<0.0001$ \\
\hline Girls $22-24$ Gy & $\begin{array}{l}-0.70(0.16) \\
{[<0.0001]}\end{array}$ & $\begin{array}{l}-0.17(0.12) \\
{[0.18]}\end{array}$ & $\begin{array}{l}0.22(0.16) \\
{[0.2]}\end{array}$ & 0.0005 & 0.01 \\
\hline Boys $18-20 \mathrm{~Gy}$ & $\begin{array}{l}-0.40(0.16) \\
{[0.01]}\end{array}$ & $\begin{array}{l}0.37(0.16) \\
{[0.03]}\end{array}$ & $\begin{array}{l}0.27(0.18) \\
{[0.2]}\end{array}$ & $<0.0001$ & 0.70 \\
\hline Boys $22-24$ Gy & $\begin{array}{l}-0.17(0.28) \\
{[0.55]}\end{array}$ & $\begin{array}{l}0.48(0.16) \\
{[0.005]}\end{array}$ & $\begin{array}{l}0.14(0.19) \\
{[0.4]}\end{array}$ & 0.02 & 0.14 \\
\hline
\end{tabular}


Table 3 Mean body mass index standard deviation(BMI z) score of unirradiated patients

\begin{tabular}{|c|c|c|c|c|c|}
\hline & \multicolumn{3}{|c|}{$\begin{array}{l}\text { Mean (SE) patient BMI } z \text { score [p value for difference from } \\
\text { population standards] }\end{array}$} & \multicolumn{2}{|c|}{$\begin{array}{l}p \text { Value for change in BMI } z \text { score during treatment and } \\
\text { between start of treatment and last follow up }\end{array}$} \\
\hline & Diagnosis & End of treatment & Last follow up & $\begin{array}{l}\text { Diagnosis to end of } \\
\text { treatment }\end{array}$ & $\begin{array}{l}\text { Start of treatment to last } \\
\text { follow up }\end{array}$ \\
\hline Girls & $\begin{array}{l}-0.12(0.19) \\
{[0.5]}\end{array}$ & $\begin{array}{l}0.70(0.17) \\
{[0.0001]}\end{array}$ & $\begin{array}{l}0.54(0.17) \\
{[0.001]}\end{array}$ & $<0.0001$ & 0.2 \\
\hline Boys & $\begin{array}{l}0.23(0.26) \\
{[0.4]}\end{array}$ & $\begin{array}{l}0.81(0.18) \\
{[<0.0001]}\end{array}$ & $\begin{array}{l}0.66(0.25) \\
{[0.01]}\end{array}$ & 0.01 & 0.5 \\
\hline
\end{tabular}

reduced $\mathrm{BMI} z$ scores at the start of treatment. Girls treated with $22-24$ Gy irradiation had $\mathrm{BMI} \mathrm{z}$ scores within the normal range at the end of treatment, but all other groups had raised BMI z scores at the end of treatment. Only girls receiving $18-20 \mathrm{~Gy}$ radiation had significantly raised BMI z scores at final height. All patient groups had a significant increase in $\mathrm{BMI} z$ scores during the time of treatment, but only girls continued to show an increase in BMI $\mathrm{z}$ scores between the end of treatment and final height.

\section{UNIRRADIATED PATIENTS}

Using regression analysis and taking $\mathrm{BMI} \mathrm{z}$ score at the start of treatment into consideration, neither age at diagnosis nor sex had a significant effect on BMI $\mathrm{z}$ score at last follow up. However, BMI z scores at last follow up were raised for both boys and girls (table 3 ). There was a significant increase in BMI $\mathrm{z}$ scores in both sexes during the time on treatment only.

OBESITY AT FINAL HEIGHT AFTER CRANIAL IRRADIATION

The prevalence of obesity (BMI z score $>2$ ) at final height was $12 \%$ in girls and $10 \%$ in boys. Girls receiving 18-20 Gy cranial irradiation had a $15 \%$ prevalence of obesity compared with $7 \%$ for those receiving 22-24 Gy. Only girls who received 18 Gy irradiation developed severe obesity (BMI z score $>3$ ), with a prevalence of $8 \%$.

\section{Discussion}

Cranial irradiation has dose dependent deleterious effects on CNS function, some of which may be greater when radiation is administered at a younger age..$^{516-18} 27$ Previously, we presented evidence that the effects of cranial irradiation in causing premature or precocious puberty are manifest particularly in girls. $^{21}$ Girls also experience greater growth impairment than boys. ${ }^{28}{ }^{29}$ The investigation of the effects of radiation on cognitive function has been bedevilled by methodological difficulties but several studies have suggested that there is a bias towards girls suffering greater cognitive dysfunction. ${ }^{19} 20$ Our study was undertaken to investigate whether the effects of cranial irradiation on BMI and obesity are also sexually dimorphic and age and radiation dose dependent.

Regression analysis demonstrated an association between raised BMI $\mathrm{z}$ score at final height, female sex, and lower radiation doses. Two groups of patients had BMI z scores that were lower than normal at diagnosis, probably reflecting the effect of the disease. During treatment all groups of patients had an increase in BMI $z$ scores. This was probably the result of a combination of improving health and the effects of glucocorticoid steroids. ${ }^{243031}$ At final height, only girls who received the lower radiation dose (18-20 Gy) had raised BMI z scores.

To examine whether the long term sequelae of the treatment of ALL resulted in obesity we used a BMI $z$ score of $>2$ as a definition of obesity and $>3$ as a definition of severe obesity. Similar proportions of male and female patients were found to be obese at final height ( $12 \%$ for girls and $10 \%$ for boys), but only girls who received 18-20 Gy cranial irradiation became severely obese, with a prevalence of $8 \%$.

Our study has the advantage of large numbers of patients and the use of up to date reference data on BMI in normal UK children. One previous UK study found a higher prevalence of obesity in female leukaemia survivors when patients were assessed four years after diagnosis using normal data from French children. ${ }^{32}$ However, BMIs are higher in UK children than French children at the same age and they have increased over the 25 years since the data were last compiled. ${ }^{33}{ }^{34}$ Another study, including children surviving a number of different malignancies, followed up for a median of 12.5 years, also found that only female patients were significantly heavier than controls. ${ }^{35}$

Two previous studies of obesity at final height after treatment for ALL found the prevalence of obesity to be $\sim 50 \%$ in both boys and girls. ${ }^{22}{ }^{23}$ Both studies included smaller numbers of patients, older reference values for BMI values, and less strict criteria for defining obesity. Reanalysing our data using the 90th centile of the reference values used by Didi et $a l,{ }^{22}$ the prevalence of obesity in our study group increased to $35 \%$ in girls and $28 \%$ in boys. Clinical obesity in adults is diagnosed when the BMI is greater than $30 \mathrm{~kg} / \mathrm{m}^{2}$. Applying this definition to our data, $9 \%$ of cranially irradiated girls and 3\% of irradiated boys were obese at final height. Fourteen per cent of girls treated with 18-20 Gy cranial irradiation had BMIs greater than $30 \mathrm{~kg} / \mathrm{m}^{2}$ compared with $2 \%$ for those who received the higher radiation dose.

Our data showed no correlation between the age at treatment and the BMI $\mathrm{z}$ score at final height. However, we believe that the association of obesity with female sex may, in part, be determined by age related cerebral development, which differs in boys and girls. Glial multiplication and differentiation with the development of myelinated neuronal 
connections continues after birth and is most active in younger children. ${ }^{36}$ There is also evidence that some areas of the brain mature much earlier in boys than in girls. ${ }^{37}$ Therefore, it is possible that the boys in our study were relatively resistant to an increase in BMI z score because the male brain has already reached a crucial level of maturity before the age at which leukaemia is diagnosed (typically, 2-4 years). Thus, the higher prevalence of adverse CNS effects in girls may reflect a longer, or later, period of maximum vulnerability.

Early vulnerability of the male hypothalamus has been demonstrated in animal studies, where alterations of hypothalamic function associated with obesity have been induced in utero in males, but not in females. ${ }^{38}$ Animal models have also shown that the brain responds differently to neurotoxic insults depending on the hormonal environment which, in turn, is dependent on the development of the hypothalamo-pituitary-gonadal axis at the time of exposure. ${ }^{39}$ Whether this is a factor in prepubertal children is uncertain.

Many of the adverse effects of radiotherapy on the CNS become more prevalent with increasing radiation dose. ${ }^{17} 1840$ However, we have shown that only girls who received the lower radiation dose (18-20 Gy) develop severe obesity. We suggest that this relatively low dose of radiation leads to damage of a radiosensitive pathway (probably hypothalamic) involved in the regulation of thermogenesis (for example, in the ventromedial nuclei causing increased parasympathetic and reduced sympathetic activity) or satiety (involving, for example, the paraventricular nuclei). ${ }^{41}$ Additional radiotherapy may result in damage to other less sensitive pathways, negating this effect.

Neurological complications after chemotherapy, without cranial irradiation, are also increasingly being recognised, particularly when high doses have been used. ${ }^{42}$ To distinguish between the effects caused by radiotherapy and those caused by chemotherapy we included an unirradiated group of patients, although numbers were smaller and follow up to final height has not yet been possible. Both boys and girls had an increase in BMI z scores over the course of treatment. Both had significantly raised BMI z scores more than four years after diagnosis, but future follow up will be required to determine if both sexes are similarly affected in the long term.

Growth hormone deficiency is a recognised complication of cranial irradiation and is known to cause an increase in fat mass, with a decrease in lean body mass and an increase in waist-hip ratio. ${ }^{44}$ However, we think that this is an unlikely explanation for the results seen in our study population. Although girls' growth is more impaired than that of boys after cranial irradiation, this is likely to have many causes, with a major contribution from the effects of premature puberty. ${ }^{28}{ }^{29}$ No study has reported growth hormone deficiency to be more common in girls than in boys. Furthermore, growth hormone deficiency is more likely to occur at much higher doses of radiation, such as $45 \mathrm{~Gy},{ }^{45}$ and, although neurosecretory dysfunction is reported at the lower doses used in the treatment of ALL, ${ }^{46}$ it is probably less at 18-20 Gy than at 22-24 Gy. ${ }^{47}$

We conclude that increases in BMI and severe obesity are late effects of chemoradiotherapy predominately affecting female survivors of ALL. The risk is greatest for those who received $18-20$ Gy radiation and it is noteworthy that $14 \%$ of these patients had a BMI $>30 \mathrm{~kg} / \mathrm{m}^{2}$ in their early adult life. Given the propensity for obesity in the UK to increase with age, together with its associated morbidity, it is imperative that these patients are followed up long term.

FC was supported by Pharmacia \& Upjohn and ADL by the MRC. Additional funding was generously provided by the Special Trustees of St George's Hospital, the REACH fund of Great Ormond Street Hospital for Children, and The Royal Marsden Hospital Childrens Unit.

1 Parkin DM, Stiller CA, Draper GJ, et al. The international incidence of childhood cancer. Int $\mathcal{F}$ Cancer 1988;42:51120.

2 Aur RJA, Simone J, Hustu HO, et al. Central nervous system therapy and combination chemotherapy of childhood lymphocytic leukaemia. Blood 1971;37:272-81.

3 Chessells JM, Bailey CC, Richards S. MRC UKALL X. The UKALL protocol for childhood ALL: 1985-1990. The Medical Research Council working party on childhood leukaemia. Leukaemia 1992;6(suppl 2):157-61.

4 Schriock EA, Schell MJ, Carter M, et al. Abnormal growth patterns and adult short stature in 115 long-term survivors of childhood leukaemia. F Clin Oncol 1991;9:400-5.

5 Shalet SM. Endocrine consequences of treatment of malignant disease. Arch Dis Child 1989;64:1635-41.

6 Riccardi R, Brouwers P, Di Chiro G, et al. Abnormal computed tomography brain scans in children with acute pumphoblastic leukaemia: serial long-term follow-up. f Clin Oncol 1985;3:12-18.

7 Paakko E, Talvensaari K, Phytinen J, et al. Late cranial MRI fter cranial irradiation in survivors of childhood cancer. Neuroradiology 1994;36:652-5.

8 Roman DD, Sperduto PW. Neuropsychological effects of cranial irradiation: current knowledge and future directions. Int $\mathcal{F}$ Radiat Oncol Biol Phys 1995;31:983-98.

9 Ball WS, Prenger EC, Ballard ET. Neurotoxicity of radio/chemotherapy in children: pathologic and MR correlation. AfNR Am $\mathcal{F}$ Neuroradiol 1992;13:761-76.

10 Caveness WF. Experimental observations: delayed necrosis in the monkey brain. In: Gilbert MA, Kagan AR, eds. Radiation damage to the nervous system. New York: Raven Press, 1980:1-36.

11 Reinhold HS, Calvo W, Hopewell JW, et al. Development of blood vessel-related radiation damage in the fembria of the blood vessel-related radiation damage in the fembria of the
central nervous system. Int $\mathcal{F}$ Radiat Oncol Biol Phys 1990; 18:37-42.

12 Withers HR, Peters LJ, Kogeinik HS. The pathobiology of ate effects of irradiation. In: Meyne RE, Withers HR, eds. Radiation biology in cancer research. New York: Raven, 1980: $439-48$

13 Crampton MR, Layton DD. Delayed radionecrosis of brain following therapeutic x-radiation of the pituitary. Brain 1961;84:58-101.

14 Ordy JM, Samorajski T, Horrocks LA, et al. Changes in memory, electrophysiology, neurochemistry and neuronal ultrastructure after deuteron irradiation of the brain in C57B1/10 mice. F Neurochem 1968;15:1245-56.

15 Phillips PC, Moeller JR, Sidtis JJ, et al. Abnormal cerebral glucose metabolism in long-term survivors of childhood glucose metabolism in long-term survivors of childhood

16 Meadows AT, Gallagher JA, Bunin GR. Late effects of early Meadows AT, Gallagher JA, Bunin GR. Late effects of early
childhood cancer therapy. Br f Cancer 1992;66 (suppl 18):92-5.

17 Silber JH, Radcliffe J, Peckham V, et al. Whole brain irradiation and decline in intelligence: the influence of dose and age on IQ score. F Clin Oncol 1992;10:1390-6.

18 Shalet SM, Beardwell CG, Pearson D, et al. The effect of varying doses of cerebral irradiation on growth hormone production in childhood. Clin Endocrinol 1976;5:287-90.

19 Waber DP, Urion DK, Tarbell NJ, et al. Late effects of central nervous system treatment of acute lymphoblastic leukaemia in childhood are sex-dependant. Dev Med Child Neurol 1990;32:238-48.

20 Christie D, Leiper AD, Chessells JM, et al. Intellectual performance after presymptomatic cranial radiotherapy for leukaemia: effects of age and sex. Arch Dis Child 1995;73:136-40.

21 Leiper AD, Stanhope R, Kitching P, et al. Precocious and premature puberty associated with treatment of acute lymphoblastic leukaemia. Arch Dis Child 1987;62:1107-12. 
22 Didi M, Didcock E, Davies HA, et al. High incidence of obesity in young adults after treatment of acute lympho-

23 Schell MJ, Ochs J, Schroick EA, et al. A method of predicting adult height and obesity in long-term survivors of childhood acute lymphoblastic leukaemia. F Clin Oncol 1992;10:128-33

24 Groot-Loonen JJ, Otten BJ, Van't Hoff MA, et al. Influence of treatment modalities on body weight in acute lymphoblastic leukaemia. Med Pediatr Oncol 1996;27:92-7.

25 Cole TJ, Freeman JV, Cole TJ, et al. Body mass index reference curves for the UK, 1990. Arch Dis Child 1995;73:259.

26 Cole TJ, Green PJ. Smoothing reference centile curves: the LMS method and penalised likelihood. Stat Med 1992;11: 1305-19.

27 Smibert E, Anderson V, Godber T, et al. Risk factors for educational and intellectual sequelae of cranial irradiation in childhood acute lymphoblastic leukaemia. Br f Cancer 1996;73:825-30.

28 Uruena M, Stanhope R, Chessells JM, et al. Impaired pubertal growth in acute lymphoblastic leukaemia. Arch pubertal growth in acute

29 Cicognani A, Cacciari E, Rosito P. Longitudinal growth and final height in long-term survivors of childhood leukaemia. Eur F Pediatr 1994;153:726-30

30 Stallings VA, Vaisman N, Chan HSL, et al. Energy matabolism in children with newly diagnosed acute lymphoblastic leukaemia. Pediatr Res 1989;26:164-57.

31 Sewell RG, Gallus JA, Nanry KP. Prednisolone effects upon body and organ weights, water intake and several behaviours. Pharmacol Biochem Behav 1982;17:1225-31.

32 Odame I, Reilly JJ, Gibson BES, et al. Patterns of obesity in boys and girls after treatment for acute lymphoblastic leukaemia. Arch Dis Child 1994;71:147-9.

33 White EM, Wilson AC, Greene SA, et al. Body mass index centile charts to assess fatness of British children. Arch Dis Child 1995;72:38-41.

34 Gulliford MC, Rona RJ, Chinn S. Trends in body mass index in young adults in England and Scotland from 1973 index in young adults in England and Scotland from 1973

35 Talvensaari KK, Knip M, Lanning P, et al. Clinical characteristics and factors affecting growth in long-term survivor of cancer. Med Pediatr Oncol 1996;26:166-72.
36 Holmes GL. Morphological and physiological maturation of the brain in the neonate and young child. $f$ Clin Neurophysiol 1986;3:209-38.

37 Goldman PS, Crawford HT, Stokes LP, et al. Sex-dependant behavioural effects of cerebral cortical lesions in the developing rhesus monkey. Science 1974;186:540-2.

38 Jones AP, Pothos EN, Rada P, et al. Maternal hormone manipulations in rats cause obesity and increase medial hypothalamic norepinephrine release in male offspring. Brain Res Dev Brain Res 1995;88:127-31.

39 McEwen BS. Actions of sex hormones on the brain: "organisation" and "activation" in relation to functional teratology. Prog Brain Res 1988;73:121-34.

40 Littley MD, Shalet SM, Beardwell CG, et al. Radiationnduced hypopituitarism is dose-dependant. Clin Endocrinol 1989;31:363-73.

41 Bray GA. Genetic, hypothalamic and endocrine features of clinical and experimental obesity. Prog Brain Res 1992;93: 333-41.

42 Bleyer WA, Griffen TW. White matter necrosis, mineralizing angiopathy and intellectual abilities in survivors of childhood leukaemia. In: Gilbert MA, Kegan AR, eds. Radiation damage to the nervous system. New York: Raven Press, 1980:155-74.

43 Mulhern RK, Fairclough D, Ochs J. A prospective comparison of neuropsychological performance of children surviving leukaemia who received 18-Gy, 24-Gy, or no cranial irradiation. F Clin Oncol 1991;9:1348-56.

44 Salomon F, Cuneo RC, Hesp R, et al. The effects of treatment with recombinant growth hormone on body composition and metabolism in adults with growth composition and metabolism in adults with growt
hormone deficiency. N Engl f Med 1989;321:1797-803.

45 Clayton PE, Shalet SM. Dose dependency of time of onset of radiation-induced growth hormone deficiency. $\mathcal{F}$ Pediatr 1991;118:226-8.

46 Crowne EC, Moore C, Wallace WHB, et al. A novel variant of growth hormone $(\mathrm{GH})$ insufficiency following low dose cranial irradiation. Clin Endocrinol 1992;36:59-68.

47 Stubberfield TG, Byrne GC, Jones TW. Growth and growth hormone secretion after treatment for acute lymphoblastic leukaemia in childhood: $18-$ Gy versus $24-G y$ cranial irradiation. $\mathcal{F}$ Pediatr Hematol Oncol 1995;17:167-71. 